\title{
ESTUDO DA REGENERAÇÃO NATURAL, BANCO DE SEMENTES E CHUVA DE SEMENTES NA RESERVA GENÉTICA FLORESTAL DE CAÇADOR, SC
}

\section{STUDY ON NATURAL REGENERATION, SEED BANK AND SEED RAIN IN THE GENETIC RESERVE FOREST OF CAÇADOR, SC}

\author{
Silvana Lucia Caldato ${ }^{1}$ Paulo Alfonso Floss ${ }^{2}$ Dorli Mário Da Croce ${ }^{2}$ Solon Jonas Longhi ${ }^{3}$
}

\section{RESUMO}

Este estudo foi realizado na Reserva Genética Florestal de Caçador, no Estado de Santa Catarina no período de agosto de 1995 a janeiro de 1996. Para o estudo da regeneração natural foram instaladas 10 parcelas de $250 \mathrm{~m}^{2}(10 \mathrm{~m} \times 25 \mathrm{~m})$. No interior das mesmas foram coletados a camada de solo juntamente com a serapilheira em até $3 \mathrm{~cm}$ de profundidade em 40 pontos amostrais de $0,5 \mathrm{~m} \times 0,5 \mathrm{~m}$ para a análise do banco de sementes no solo, e instalados 20 coletores com área de $0,5 \mathrm{~m} \times 0,5 \mathrm{~m}$ para a avaliação da chuva de sementes. Os resultados mostram que apesar da Araucaria angustifolia ser a espécie dominante no estrato superior da floresta não apresenta indivíduos na regeneração natural e a Mimosa scabrella foi a espécie arbórea mais importante presente no banco de sementes no solo. As relações entre os três parâmetros avaliados evidenciam uma distribuição irregular das espécies na área de estudo.

Palavras-chave: Regeneração natural, Banco de sementes, Floresta Ombrófila Mista, Floresta de araucária.

\section{SUMMARY}

The study was made in the Genetic Reserve Forest of Caçador, in the State of Santa Catarina, Brazil. In the study of natural regeneration were established 10 plots with an area of 250 sq $\mathrm{m}(25 \mathrm{~m} \times 10 \mathrm{~m})$. Inside the plots, were collected a layer of soil with foliage up to $3 \mathrm{~cm}$ of depth in the 40 samples with an area of $0,5 \mathrm{~m} \times 0,5 \mathrm{~m}$ to the analyse of the seed bank in the soil. Moreover, 20 traps with an area of $0,5 \mathrm{~m} \times 0,5 \mathrm{~m}$ were established to evaluate seed rain. The results obtained showed that although Araucaria angustifolia was the dominant species of the canopy layer, it did not appear in the natural regeneration layer. On the other hand, Mimosa scabrella was the most

1. Acadêmico do Curso de Graduação em Engenharia Florestal. UFSM. Bolsista do CNPq. 97.119-900. Santa Maria. RS.

2. Engenheiros Florestais, M.Sc., Pesquisadores da EPAGRI S.A./CPPP, C. Postal 791. São Cristóvão. 89.801-970. Chapecó. SC.

3. Engenheiro Florestal, Doutorando, Prof. Titular do Departamento de Ciências Florestais. UFSM. 97.119900. Santa Maria. RS. 
important tree species found in the seed bank in the soil. The relation between the three parameters evaluated suggested an irregular distribution of the species in the study site.

Key words: Natural regeneration, Seed bank, Araucaria Forest.

\section{INTRODUÇÃO}

A crescente exploração dos recursos naturais tem levado a perdas de muitas espécies, sem antes ter-se estudado ou mesmo tomado conhecimento de sua existência. Obviamente que uma vez extinta, a espécie não mais reaparece. Pela teoria da seleção natural (DARWIN, 1985), a extinção das formas antigas e a produção de novas formas aperfeiçoadas estão intimamente correlacionadas. No entanto, o que era para ser um processo lento e equilibrado, a ação antrópica alterou este equilíbrio e acelerou bruscamente o processo de extinção. $O$ estudo em áreas silvestres não alteradas é essencial para que se tenha compreensão destas complexas estruturas, dando maior ênfase a investigações com enfoque no comportamento ecológico dos seres no ecossistema.

O principal meio de regeneração das espécies tropicais dá-se através da chuva de sementes (sementes dispersadas recentemente), através do banco de sementes do solo (sementes dormentes no solo), através do banco de plântulas (plântulas estabelecidas e suprimidas no chão da floresta), e através da formação de bosque (emissão rápida de brotos e/ou raízes provenientes de indivíduos danificados) (GARWOOD, 1989).

De acordo com DANIEL \& JANKAUSKIS (1989), o entendimento dos processos de regeneração natural de florestas é importante para o sucesso do seu manejo, o qual necessita de informações básicas em qualquer nível de investigação. A recolonização pela vegetação em um ambiente perturbado ocorre principalmente através dos bancos de sementes no solo, mantendo este um papel fundamental no equilíbrio dinâmico da floresta (SCHMITZ, 1992). Denomina-se banco de sementes no solo a todas as sementes viáveis no solo ou associadas à serapilheira para uma determinada área num dado momento. É um sistema dinâmico com entrada de sementes através da chuva de sementes e dispersão, podendo ser transitório, com sementes que germinam dentro de um ano após o início da dispersão, ou persistente, com sementes que permanecem no solo por mais de um ano. Esta persistência personifica segundo SIMPSON et al.(1989), uma reserva do potencial genético acumulado.

VÁSQUEZ-YANES \& OROZCO-SEGOVIA [ 19-- ], em estudos sobre a viabilidade de sementes em Floresta Úmida Tropical, citam ROBERTS (1973), que dividiu as sementes em dois grupos: ortodoxas e recalcitrantes. Sementes ortodoxas são descritas como relativamente pequenas, com baixas taxas de metabolismo e respiração, permenecem com sucesso por um longo período de tempo com baixa umidade e baixa temperatura. Sementes recalcitrantes são geralmente grandes, com altas taxas de metabolismo e respiração, não sobrevivem sob condições secas ou de alta umidade, sua viabilidade é muito curta, somente são capazes de sobreviver em condições especiais de armazenamento. A maioria das sementes das espécies arbóreas de florestas úmidas do mundo são recalcitrantes. Como exemplo de sementes ortodoxas cita-se as das espécies pioneiras, que entram em atividade quando há a formação de clareiras.

Florestas que raramente sofrem perturbações tendem a ter densidades mais baixas em seu banco de sementes. SAULEI \& SWAINE (1988) apud GORRESIO-ROIZMAN (1993) estudaram 
o estabelecimento do banco de sementes no solo pela chuva de sementes, durante dois anos na Nova Guiné, e concluíram que o banco de sementes em floresta primária é constituído principalmente por sementes depositadas por plantas matrizes anteriormente presentes na floresta. No entanto, a perturbação contínua de uma área pode levar ao esgotamento progressivo do banco de sementes, tornando o local com restrições para regenerar na primeira fase da sucessão (KAGEYAMA et al., 1989). Esses locais muito abertos e ensolarados propiciam a entrada de gramíneas, que impedem a regeneração natural da floresta ( NOGUEIRA \& NOGUEIRA, 1991).

A classificação das espécies feita por BUDOWSKI (1965), em grupos ecológicos de acordo com a sucessão foi a seguinte: (i) - pioneiras e secundárias iniciais, (ii) - secundárias tardias, (iii) clímax. Segundo o autor, o mecanismo de disseminação das sementes de espécies pioneiras e secundárias iniciais é muito eficiente. As secundárias tardias são tolerantes à sombra na fase jovem e tornam-se intolerantes na medida que crescem. Nos estágios de sucessão mais avançados surgem as espécies clímax, que são tolerantes à sombra na fase adulta, apresentam abundância de regeneração, e a sua disseminação das sementes é feita por gravidade.

O presente trabalho teve por objetivo estudar as relações quali-quantitativas existentes entre a regeneração natural, banco de sementes no solo e chuva de sementes na Reserva Genética Florestal de Caçador, SC, inserida numa área de Floresta Ombrófila Mista primária.

\section{MATERIAIS E MÉTODOS}

A Reserva Genética Florestal de Caçador, contendo uma área de 1.120,30 ha está inserida na Estação Experimental de Caçador, SC, pertencente à EMBRAPA e cedida em regime de comodato à EPAGRI S.A. Para a avaliação da regeneração natural, dois tipos florestais principais existentes no local: I- com predominância da araucária no estrato superior e o II- com predominância de outras espécies nativas (DA CROCE, 1991) foram considerados. Foram instaladas 10 parcelas permanentes de $250 \mathrm{~m}^{2}(25 \times 10 \mathrm{~m})$, ficando distribuídas 5 parcelas em cada tipo florestal. Foram identificadas todas as plantas com altura superior a $10 \mathrm{~cm}$ e DAP inferior a $10 \mathrm{~cm}$, divididas em três categorias de tamanho: (i) - Ct I $=$ de 0,1 - 0,50 $\mathrm{m}$ de altura, (ii) - Ct II =0,51 - até $3 \mathrm{~m}$ de altura, (iii) $-\mathrm{Ct}$ III $=$ de $3 \mathrm{~m}$ de altura a $9,9 \mathrm{~cm}$ de DAP.

Avaliaram-se os índices de freqüência, abundância e categoria de tamanho em suas formas relativas, conforme FINOL (1971), LONGHI (1980) e CARVALHO (1984):

$$
\begin{aligned}
& A b \text { abs }=\frac{N^{o} \text { de plantas de cada espécie }}{N^{o} \text { de ha}} \\
& A b \%=\frac{A b \text { abs }}{N^{o} \text { total de plantas por ha }} \times 100
\end{aligned}
$$

Frabs $=\%$ de sub-parcela sem que ocorreu uma espécie

$$
\begin{aligned}
& F r \%=\frac{F r a b s}{\sum F r A b s} X 100 \\
& C t a b s=V F(C t I) \times n(C t I)+V F(C t I I) \times n(C t I I)+V F(C t I I \times n(C t I I I)
\end{aligned}
$$




$$
C t \%=\frac{C t a b s}{\sum C t a b s} \times 100
$$

Onde: $A b a b s=$ abundância absoluta; $A b \%=$ abundância relativa, $F r$ abs $=$ freqüência absoluta, $\mathrm{Fr} \%=$ freqüência relativa, $C t$ abs = categoria de tamanho absoluta, $V F=$ valor fitossociológico simplificado (dividido por 10) que corresponde a proporção de cada indivíduo em cada categoria de tamanho, $\mathrm{CtI}=$ categoria de tamanho $\mathrm{I}, \mathrm{CtII}=$ categoria de tamanho II, CtIII = categoria de tamanho III, $\mathrm{n}=$ número de indivíduos e $\mathrm{Ct} \%=$ categoria de tamanho relativa.

Segundo FINOL (1971), um novo parâmetro de regeneração natural relativa para cada espécie $(\mathrm{Rn} \%)$, pode ser obtido por:

$$
R n \%=\frac{A b \%+F r \%+C t \%}{3}
$$

Para análise do banco de sementes no solo foram amostrados 40 pontos, distribuídos aleatoriamente no interior das parcelas utilizadas para avaliação da regeneração natural, sendo 20 pontos em cada tipo florestal. Cada ponto teve definida uma área superficial de $0,5 \mathrm{~m} \times 0,5 \mathrm{~m}$, onde foram coletadas a serapilheira e a camada de solo numa profundidade média de $3 \mathrm{~cm}$. A coleta das amostras de solo foi realizada no mês de agosto de 1995.

O experimento foi montado em viveiro a pleno sol e com sombrite a $70 \%$. As amostras de uma mesma parcela foram homogeneizadas e após divididas nos dois tratamentos (a pleno sol e sombrite $70 \%$ ), ficando acondicionadas em canteiros, totalizando 40 parcelas de $1 \mathrm{~m}^{2}$ cada. Os canteiros devidamente limpos receberam uma camada de $5 \mathrm{~cm}$ de espessura de areia esterelizada, onde posteriormente foram coletados o solo e a serapilheira contendo o banco de sementes, separados um do outro. A irrigação foi feita diariamente, de acordo com a necessidade. À medida que as plântulas foram crescendo até um tamanho que fosse possível sua identificação, foram feitas as leituras quali-quantitativas.

Para cada espécie foi calculada a freqüência e abundância relativas, o índice de valor de importância (IVB) e ainda os índices de diversidade de Shanonn (H') e de equabilidade (J), conforme GORRESIO-ROIZMAN (1993), para o total de espécies obtidas, de acordo com as seguintes fórmulas:

$$
\begin{aligned}
& I V B=F r \%+A b \% \\
& H^{\prime}=-\sum p i \cdot \ln p i \\
& J=H^{\prime} / \ln S
\end{aligned}
$$

Onde: $H^{\prime}=$ índice de diversidade de Shannon, $p i=n i / N, n i=$ número de indivíduos amostrados, $J=$ índice de equabilidade, $S=$ número total de espécies amostradas.

Para o estudo da chuva de sementes instalou-se 20 coletores de madeira, confeccionados com tela de naylon no fundo, suspensos a aproximadamente $20 \mathrm{~cm}$ do solo e contendo uma área de $0,25 \mathrm{~m}^{2}(0,5 \mathrm{~m} \times 0,5 \mathrm{~m})$. Foram dispostos aleatoriamente dois coletores em cada parcela nas quais estudou-se o componente arbóreo e o banco de sementes. Os diásporos depositados no interior dos coletores foram recolhidos em intervalos de 30 dias durante seis meses. Após a secagem do material 
em estufa, fez-se a triagem manual com auxílio de lupa, para quali-quantificação das sementes e frutos, permitindo assim calcular a abundância e a freqüência relativas.

\section{RESULTADOS E DISCUSSÃO}

Na composição florística da regeneração natural foi observada a ocorrência de 44 espécies distribuídas em 37 gêneros de 26 famílias nas unidades amostradas (Tabela 1), sendo Myrtaceae, Lauraceae e Sapindaceae as que apresentaram maior número de espécies.

TABELA 1: Relação das espécies levantadas na regeneração natural da Floresta Ombrófila Mista da Reserva Genética Florestal de Caçador, SC.

\begin{tabular}{|c|c|c|c|}
\hline FAMÍLIA & NOME CIENTÍFICO & NOME VULGAR & HÁBITO \\
\hline Anacardiaceae & Lithraea brasiliensis L. March. & Bugreiro & arbóreo \\
\hline Annonaceae & Rollinia sp. & Ariticum & arbóreo \\
\hline Aquifoliaceae & Ilex brevicuspis Reissek & Caúna & arbóreo \\
\hline & Ilex paraguariensis St.Hil. & Erva-mate & arbóreo \\
\hline Canellaceae & $\begin{array}{l}\text { Capsicodendron dinisii (Schwacke) } \\
\text { Occhioni }\end{array}$ & Pimenteira & arbóreo \\
\hline Caprifoliaceae & Sambucus australis Cham.\& Schlecht. & Sabugueiro & arbustivo \\
\hline Compositae & $\begin{array}{l}\text { Piptocarpha angustifolia Dusen } \\
\text { Vernonia discolor (Spreng.) Less. }\end{array}$ & $\begin{array}{l}\text { Vassourão-branco } \\
\text { Vassourão-preto }\end{array}$ & $\begin{array}{l}\text { arbóreo } \\
\text { arbóreo }\end{array}$ \\
\hline Cunoniaceae & $\begin{array}{l}\text { Lamanonia speciosa (Camb.) L.B.Smith. } \\
\text { Weinmania sp. }\end{array}$ & $\begin{array}{l}\text { Guaraperê } \\
\text { Gramimunha }\end{array}$ & $\begin{array}{l}\text { arbóreo } \\
\text { arbóreo }\end{array}$ \\
\hline Elaeocarpaceae & Sloanea lasiocoma K.Schumann & Sapopema & arbóreo \\
\hline Euphorbiaceae & $\begin{array}{l}\text { Sapium glandulatum (Vell.) Pax. } \\
\text { Sebastiana klotzschiana } \\
\text { (Müll.Arg.)Müll.Arg. }\end{array}$ & $\begin{array}{l}\text { Leiteiro } \\
\text { Branquilho }\end{array}$ & $\begin{array}{l}\text { arbóreo } \\
\text { arbóreo }\end{array}$ \\
\hline Flacourtiaceae & $\begin{array}{l}\text { Casearia decandra Jacquin } \\
\text { Casearia obliqua Spreng. }\end{array}$ & $\begin{array}{l}\text { Guaçatunga } \\
\text { Guaçatunga-preta }\end{array}$ & $\begin{array}{l}\text { arbóreo } \\
\text { arbóreo }\end{array}$ \\
\hline Lauraceae & $\begin{array}{l}\text { Ocotea porosa (Ness et Mart.) L. Barroso } \\
\text { Ocotea puberula Ness } \\
\text { Ocotea pulchella Martius } \\
\text { Nectandra } \mathrm{sp} \text {. }\end{array}$ & $\begin{array}{l}\text { Imbuia } \\
\text { Canela-guaicá } \\
\text { Canela lageana } \\
\text { Canela-preta }\end{array}$ & $\begin{array}{l}\text { arbóreo } \\
\text { arbóreo } \\
\text { arbóreo } \\
\text { arbóreo }\end{array}$ \\
\hline Leguminosae & $\begin{array}{l}\text { Lonchocarpus sp. } \\
\text { Inga } \mathrm{sp} \text {. }\end{array}$ & $\begin{array}{l}\text { Timbó } \\
\text { Ingá }\end{array}$ & $\begin{array}{l}\text { arbóreo } \\
\text { arbóreo }\end{array}$ \\
\hline Meliaceae & Cedrela fissilis Vell. & Cedro & arbóreo \\
\hline Myrtaceae & $\begin{array}{l}\text { Campomanesia xanthocarpa Berg } \\
\text { Eugenia schüchiana Berg } \\
\text { Eugenia involucrata DC. } \\
\text { Eugenia pyriformis Camb. } \\
\text { Myrcianthes pungens (Berg) Legr. } \\
\text { Myrciaria } \mathrm{sp} . \\
\text { Myrcia } \mathrm{sp} \text {. }\end{array}$ & $\begin{array}{l}\text { Guabiroba } \\
\text { Guamirim-miúdo } \\
\text { Cerejeira } \\
\text { Uvaia } \\
\text { Guabiju } \\
\text { Guamirim } \\
\text { Guamirim-branco }\end{array}$ & $\begin{array}{l}\text { arbóreo } \\
\text { arbóreo } \\
\text { arbóreo } \\
\text { arbóreo } \\
\text { arbóreo } \\
\text { arbóreo } \\
\text { arbóreo }\end{array}$ \\
\hline
\end{tabular}


TABELA 1: Continuação ...

\begin{tabular}{|c|c|c|c|}
\hline FAMÍLIA & NOME CIENTÍFICO & NOME VULGAR & HÁBITO \\
\hline & Myrciaria sp. & Cambuim & arbóreo \\
\hline Myrsinaceae & Rapanea sp. & Capororoca & arbóreo \\
\hline Nyctaginaceae & Bougainvillea glabra Choisy & Primavera & arbustivo \\
\hline Palmae & $\begin{array}{l}\text { Syagrus romanzofiana (Chamisso) } \\
\text { Glassman }\end{array}$ & Coqueiro & arbóreo \\
\hline Proteaceae & Roupala brasiliensis Klotz. & Carvalho & arbóreo \\
\hline Rhamnaceae & Scutia buxifolia Reissek & Coronilha & arbóreo \\
\hline Rosaceae & Prunus sellowii Koehne & Pessegueiro-bravo & arbóreo \\
\hline Rutaceae & Zanthoxylum rhoifolium Lam. & Mamica-de-cadela & arbóreo \\
\hline \multirow[t]{3}{*}{ Sapindaceae } & Allophylus edulis (St. Hil.) Radlk. & Vacum & arbóreo \\
\hline & Cupania vernalis Camb. & Miguel-pintado & arbóreo \\
\hline & Matayba elaeagnoides Radlk. & Camboatá & arbóreo \\
\hline Winteraceae & Drimys brasiliensis Miers & Cataia & arbóreo \\
\hline Tiliaceae & Luehea divaricata Martius & Açoita-cavalo & arbóreo \\
\hline Loganiaceae & Strychnos brasiliensis (Spreng.) Mart. & Esporão-de-galo & arbustivo \\
\hline Solanaceae & Solanum sp. & Juazeiro & arbustivo \\
\hline
\end{tabular}
regeneração natural $(\mathrm{Rn} \%)$ nas suas formas relativas para as espécies mais relevantes podem ser vistos na Tabela 2. Cupania vernalis (miguel-pintado), Casearia decandra (guaçatunga), Allophylus edulis (vacum), Campomanesia xanthocarpa (guabiroba) e canelas são as espécies que estão melhor representadas nas três categorias de tamanho no Tipo Florestal I, e Casearia decandra (guaçatunga), Myrcia sp. (guamirim-branco), Ilex paraguariensis (erva-mate), Lonchocarpus sp. (timbó), Cupania vernalis (miguel-pintado), Campomanesia xanthocarpa (guabiroba) e canelas no Tipo Florestal II. Estas espécies são as que apresentam uma seqüência mais regular nas fases de crescimento e, portanto, têm maiores possibilidades de sobrevivência na estrutura futura da floresta.

As principais espécies que dominam o estrato arbóreo, como a araucária, a imbuia, a bracatinga e o cedro (DA CROCE, 1991), apresentam baixos índices de regeneração natural, ficando comprometida a sua conservação "in situ". Tais espécies, com exceção da imbuia, pertencem aos estágios iniciais de sucessão, o que torna compreensível este comportamento, pois as mesmas têm maiores exigências quanto à luminosidade na fase inicial e, portanto, necessitam de perturbações nas florestas, como, por exemplo, a abertura de uma clareira para crescerem. Porém, no caso da imbuia, que é uma espécie clímax e apresenta grande produção de frutos, este baixo índice de regeneração pode estar sendo ocasionado por algum fator alelopático.

O banco de sementes no solo foi posto a germinar e verificou-se a presença de 10 espécies de plântulas arbóreas e 8 arbustivas principais, que germinaram durante os 150 dias de avaliação após a instalação do experimento. As espécies arbóreas encontradas foram: da família Lauraceae (canela), Araucaria angustifolia (pinheiro-brasileiro), Sapium glandulatum (leiteiro), Zanthoxylum sp. (mamica-de-cadela), Mimosa scabrella (bracatinga), Prunus sellowii (pessegueirobravo), Weinmania sp. (gramimunha), Ilex paraguariensis (erva-mate), Parapiptadenia rigida 
TABELA 2: Categoria de tamanho, abundância, freqüência e regeneração natural, em suas formas relativas das principais espécies que compõem a regeneração natural da Floresta Ombrófila Mista da Reserva Genética Florestal de Caçador, SC.

\begin{tabular}{|c|c|c|c|c|c|c|c|c|}
\hline \multirow[b]{3}{*}{ Espécie } & \multicolumn{7}{|c|}{ Tipo Florestal I } & \multirow[b]{3}{*}{$\mathrm{Rn} \%$} \\
\hline & \multicolumn{3}{|c|}{$\mathrm{N}^{\circ}$ de árvores } & \multirow[b]{2}{*}{$\mathrm{Ct} \mathrm{ab}$} & \multirow[b]{2}{*}{$\mathrm{Ct} \%$} & \multirow[b]{2}{*}{$\mathrm{Ab} \%$} & \multirow[b]{2}{*}{$\mathrm{Fr} \%$} & \\
\hline & $\mathrm{Ct}$ III & Ct II & $\mathrm{Ct} \mathrm{I}$ & & & & & \\
\hline Guaçatunga & 14 & 13 & 134 & 1134,7 & 16,20 & 16,28 & 12,54 & 15,01 \\
\hline Miguel-pintado & 10 & 17 & 106 & 905,9 & 12,90 & 13,45 & 8,80 & 11,72 \\
\hline Canela (várias) & 3 & 4 & 102 & 853,0 & 12,20 & 11,02 & 4,53 & 9,25 \\
\hline Guabiroba & 2 & 6 & 49 & 415,3 & 5,93 & 5,77 & 7,79 & 6,50 \\
\hline Capororoca & 1 & 3 & 65 & 543,8 & 7,77 & 6,98 & 4,48 & 6,41 \\
\hline Guamirim-branco & 1 & 16 & 44 & 386,4 & 5,52 & 6,17 & 5,28 & 5,66 \\
\hline Pessegueiro-bravo & 0 & 3 & 66 & 551,7 & 7,88 & 6,98 & 1,96 & 5,61 \\
\hline Camboatá & 0 & 1 & 33 & 275,2 & 3,93 & 3,44 & 1,96 & 3,11 \\
\hline Esporão-de-galo & 1 & 9 & 10 & 95,1 & 1,36 & 2,02 & 5,28 & 2,89 \\
\hline Erva-mate & 1 & 6 & 18 & 157,6 & 2,25 & 2,53 & 3,78 & 2,85 \\
\hline Sapopema & 0 & 1 & 25 & 208,8 & 2,98 & 2,63 & 1,96 & 2,52 \\
\hline Vacum & 3 & 14 & 8 & 85,8 & 1,22 & 2,53 & 3,78 & 2,51 \\
\hline Total & & & & & $80 \%$ & $80 \%$ & $62 \%$ & $74 \%$ \\
\hline & & & o Flore & tal II & & & & \\
\hline Canela (várias) & 8 & 27 & 496 & 4283,8 & 22,00 & 20,41 & 5,79 & 16,07 \\
\hline Pessegueiro-bravo & 1 & 1 & 437 & 3746,5 & 19,24 & 16,87 & 2,95 & 13,02 \\
\hline Miguel-pintado & 4 & 42 & 219 & 1925,9 & 9,89 & 10,18 & 6,67 & 8,91 \\
\hline Guaçatunga & 13 & 17 & 206 & 1788,6 & 9,19 & 9,07 & 7,94 & 8,73 \\
\hline Camboatá & 1 & 50 & 169 & 1505,6 & 7,73 & 8,45 & 4,91 & 7,03 \\
\hline Guamirim-branco & 11 & 28 & 139 & 1226,3 & 6,30 & 6,84 & 6,67 & 6,60 \\
\hline Erva-mate & 8 & 20 & 63 & 565,0 & 2,90 & 3,50 & 8,42 & 4,95 \\
\hline Timbó & 7 & 29 & 59 & 540,7 & 2,78 & 3,65 & 5,16 & 3,86 \\
\hline Guabiju & 0 & 21 & 82 & 726,7 & 3,73 & 3,96 & 1,13 & 2,94 \\
\hline Guabiroba & 2 & 13 & 39 & 349,6 & 1,80 & 2,07 & 4,81 & 2,89 \\
\hline Sapopema & 0 & 2 & 79 & 679,3 & 3,99 & 3,11 & 1,94 & 2,85 \\
\hline Capororoca & 1 & 4 & 57 & 493,3 & 2,53 & 2,38 & 3,93 & 2,95 \\
\hline Total & & & & & $92 \%$ & $91 \%$ & $60 \%$ & $81 \%$ \\
\hline
\end{tabular}

$\mathrm{Ct} \mathrm{I}=$ de 0,1 - 0,50 $\mathrm{m}$ de altura; $\mathrm{Ct} \mathrm{II}=0,51$ - até $3 \mathrm{~m}$ de altura; $\mathrm{Ct} \mathrm{III}=$ de $3 \mathrm{~m}$ de altura a 9,9 $\mathrm{cm} \mathrm{de} \mathrm{DAP;} \mathrm{Ct} \mathrm{ab=}$ categoria de tamanho absoluta; $\mathrm{Ct} \%=$ categoria de tamanho relativa; $\mathrm{Ab} \%=$ abundância relativa; $\mathrm{Fr} \%=\mathrm{freqüência}$ relativa; $\mathrm{Rn} \%=$ regeneração natural relativa.

(angico-vermelho) e Rapanea ferruginea (capororoca). GORRESIO-ROIZMAN (1993) realizou experimento semenhante com solo de floresta secundária e encontrou 18 espécies de plântulas arbóreas. A autora defende que as florestas secundárias tendem a ter os maiores valores de densidade no banco de sementes no solo por apresentarem graus variados de abertura no dossel, o que facilita o ingresso de sementes e abastece continuamente o estoque no solo. Mesmo sendo difícil uma comparação direta entre estes trabalhos, devido às diferenças metodológicas, esta teoria 
coincide com os números encontrados na Reserva Genética Florestal de Caçador que, por ser uma floresta primária, apresentou menor número de espécies arbóreas germinadas a partir de seu banco de sementes do solo.

Na Tabela 3, encontram-se os cálculos de freqüência e abundância relativas e o índice de importância do banco de sementes no solo (IVB). Observa-se que no Tipo Florestal I há um menor valor quali-quantitativo de espécies e o predomínio de espécies de estágios iniciais da sucessão, sendo destacado o IVB para Solanum sp. (fumo-bravo) e Mimosa scabrella (bracatinga) que são pioneiras, e Prunus sellowii (pessegueiro-bravo), uma secundária inicial. No Tipo Florestal II há maior diversidade de espécies nos estágios mais avançados da sucessão, como as canelas, por exemplo. No Tipo Florestal II o índice de diversidade e de equabilidade, incluindo espécies

TABELA 3: Número de indivíduos, freqüência e abundância relativas, índice de valor de importância do banco de sementes no solo para os dois tipos florestais da Reserva Genética Florestal de Caçador, SC.

\begin{tabular}{l|c|r|r|r|r|r|r|r}
\hline \multirow{2}{*}{ Espécie } & \multicolumn{4}{|c|}{ Tipo Florestal I } & \multicolumn{4}{c}{ Tipo Florestal II } \\
\cline { 2 - 9 } & $\mathrm{N}^{\circ}$ & \multicolumn{1}{c}{$\mathrm{Fr} \%$} & $\mathrm{Ab} \%$ & $\mathrm{IVB}$ & $\mathrm{N}^{\circ}$ & $\mathrm{Fr} \%$ & $\mathrm{Ab} \%$ & $\mathrm{IVB}$ \\
\hline Pessegueiro-bravo & 5 & 12,00 & 9,62 & 21,62 & 33 & 13,56 & 17,65 & 31,21 \\
Bracatinga & 7 & 8,00 & 13,46 & 21,46 & 73 & 22,03 & 22,03 & 61,07 \\
Canela & 1 & 4,00 & 1,92 & 5,92 & 20 & 15,25 & 10,70 & 25,95 \\
Leiteiro & & & & & 13 & 6,78 & 6,95 & 13,73 \\
Capororoca & & & & & 1 & 1,69 & 0,53 & 2,22 \\
Gramimunha & & & & & 1 & 1,69 & 0,53 & 2,22 \\
Mamica-de-cadela & 1 & 4,00 & 1,92 & 5,92 & 1 & 1,69 & 0,53 & 2,22 \\
Araucária & 2 & 8,00 & 3,85 & 11,85 & & & & \\
Erva-mate & & & & & 6 & 3,40 & 3,22 & 6,62 \\
Angico-vermelho & & & & & 2 & 3,40 & 1,07 & 4,47 \\
Esporão-de-galo & 2 & 4,00 & 3,85 & 7,85 & & & & \\
Buva & 2 & 8,00 & 3,85 & 11,85 & & & & \\
Fumo-bravo & 27 & 32,00 & 51,92 & 83,92 & 4 & 5,08 & 2,14 & 7,22 \\
Quebra-pedra & 1 & 4,00 & 1,92 & 5,92 & 18 & 10,17 & 9,63 & 19,80 \\
Juazeiro & 3 & 12,00 & 5,77 & 17,77 & 4 & 3,40 & 2,14 & 5,54 \\
Pariparoba & & & & & 7 & 5,08 & 3,74 & 8,82 \\
Cipón & 1 & 4,00 & 1,92 & 5,92 & 1 & 1,69 & 0,53 & 2,22 \\
Sabugueiro & & & & & 1 & 1,69 & 0,53 & 2,22 \\
\hline Total & 52 & $100 \%$ & $100 \%$ & & 187 & $100 \%$ & $100 \%$ & \\
\hline
\end{tabular}

$\mathrm{N}^{\circ}=$ número de indivíduos; $\mathrm{Fr} \%=$ frequência relativa; $\mathrm{Ab} \%=$ abundância relativa; $\mathrm{IVB}=$ índice de valor de importância do banco de sementes no solo.

arbóreas e arbustivas, são maiores quando comparados ao Florestal I, $\left(H^{\prime}=1,86, J=0,68\right)$ e $\left(H^{\prime}=1,68, J=0,58\right)$, respectivamente. GORRESIO-ROIZMAN (1993) encontrou índices totais nas diferentes profundidades e do folhedo para as espécies arbóreas de $\mathrm{H}^{\prime}=1,65$ e $\mathrm{J}=0,57$. Para a autora o valor de diversidade obtido no banco de sementes reflete valores baixos de riqueza e a baixa 
equabilidade reflete a pouca equitatividade na distribuição de indivíduos de cada população. A germinação das sementes no solo e folhedo de acordo com as condições de sombra (70\%) e a pleno sol está ilustrada na Figura 1, onde se percebe uma predominância de indivíduos no solo do tipo Florestal II nas condições de sombreamento, e a menor quantidade tanto de indivíduos como de espécies foi encontrada no folhedo do tipo Florestal I.

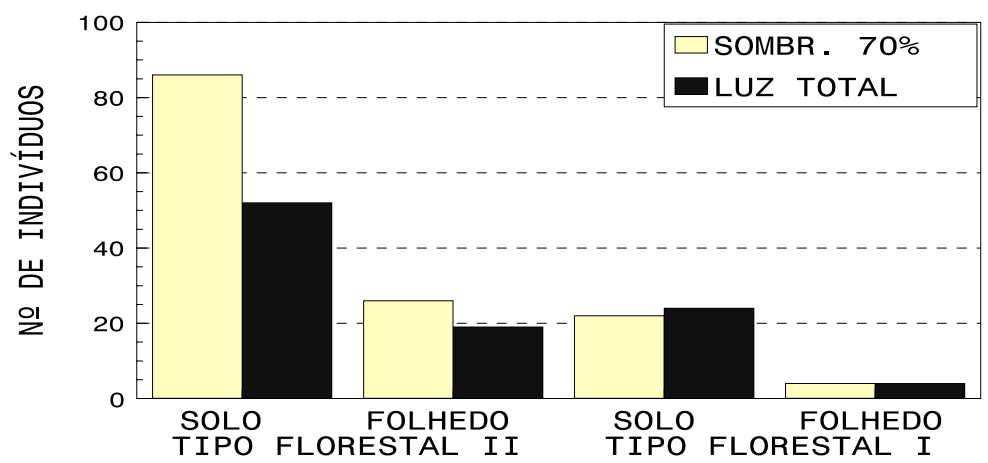

FIGURA 1: Número total de indivíduos que germinam do banco de sementes no solo, de acordo com o tipo florestal, em condições de sombreamento (SOMBR.) e luminosidade total (LUZ TOTAL) na Reserva Genética Florestal de Caçador, SC.

Nos seis meses do estudo da chuva de sementes, foram encontradas 19 espécies de frutos e sementes e destas, 9 espécies de baixa abundância, não foram identificadas (Tabela 4). Cabe

TABELA 4: Relação das espécies encontradas na chuva de sementes de uma Floresta Ombrófila Mista da Reserva Genética Florestal de Caçador, SC.

\begin{tabular}{|c|c|c|}
\hline Família & Nome científico & Nome vulgar \\
\hline Bignoniaceae & & cipó \\
\hline Canelaceae & Capsicondendron dinisii (Schwacke) Occhioni & pimenteira \\
\hline Compositae & Piptocarpha angustifolia Dusen & vassourão-branco \\
\hline Compositae & Vernonia discolor (Spreng.) Less. & vassourão-preto \\
\hline \multicolumn{3}{|l|}{ Compositae } \\
\hline Flacourtiaceae & Casearia decandra Jacquin & guaçatunga \\
\hline Lauraceae & Nectandra sp. & canela-preta \\
\hline Lauraceae & & canela \\
\hline Lauraceae & Ocotea porosa (Nees ex Mart.) L. Barroso & imbuia \\
\hline Leguminosae & Mimosa scabrella Benth. & bracatinga \\
\hline Leguminosae & Crotalaria lanceolata E. Mey & crotalária \\
\hline Myrtaceae & Myrciaria sp. & cambuim \\
\hline Myrsinaceae & Rapanea ferruginea (Ruiz \& Pavon) Mez & capororoca \\
\hline Proteaceae & Roupala brasiliensis Klotz & carvalho \\
\hline \multicolumn{3}{|l|}{ Piperaceae } \\
\hline Sapindaceae & Cupania vernalis Camb. & miguel-pintado \\
\hline Sapindaceae & Serjania sp & cipó \\
\hline Sapindaceae & Allophylus sp. & vacum \\
\hline Rosaceae & Prunus sellowii Koehne & pessegueiro-bravo \\
\hline
\end{tabular}


ressaltar que, na representação da chuva de sementes de uma floresta, os dados devem ser coletados mensalmente, por um período superior a um ano, para que se possa verificar as flutuações anuais e amostrar as espécies que não florescem anualmente.

Em relação à produção de frutos e sementes, as espécies predominantes no tipo florestal I foram: Vernonia discolor (vassourão-preto), Casearia decandra (guaçatunga), Piptocarpha angustifolia (vassourão-branco) e Capsicodendron dinisii (pimenteira) e no florestal II: Prunus sellowii (pessegueiro-bravo), Vernonia discolor e Piptocarpha angustifolia. A Tabela 5 apresenta os dados de freqüência e abundância relativas por data de coleta. Setembro foi o mês em que se verificou o menor fluxo de diásporos (frutos e sementes).

TABELA 5: Freqüência e abundância relativas dos frutos e sementes amostrados na chuva de sementes de uma Floresta Ombrófila Mista da Reserva Genética Florestal de Caçador, SC.

\begin{tabular}{|c|c|c|c|c|c|c|c|c|c|c|c|c|}
\hline \multicolumn{13}{|c|}{ Tipo Florestal I } \\
\hline Mês & \multicolumn{2}{|c|}{$08 / 95$} & \multicolumn{2}{|c|}{$09 / 95$} & \multicolumn{2}{|c|}{$10 / 95$} & \multicolumn{2}{|c|}{$11 / 95$} & \multicolumn{2}{|c|}{$12 / 95$} & \multicolumn{2}{|c|}{$01 / 96$} \\
\hline Espécie & $\mathrm{Fr} \%$ & $\mathrm{Ab} \%$ & $\mathrm{Fr} \%$ & $\mathrm{Ab} \%$ & $\mathrm{Fr} \%$ & $\mathrm{Ab} \%$ & $\mathrm{Fr} \%$ & $\mathrm{Ab} \%$ & $\mathrm{Fr} \%$ & $\mathrm{Ab} \%$ & $\mathrm{Fr} \%$ & $\mathrm{Ab} \%$ \\
\hline Camboim & & & & & & & 8,3 & 1,9 & & & & \\
\hline Canela & 14,2 & 9,1 & & & 6,3 & 0,9 & 4,2 & 1,9 & 8,3 & 0,8 & & \\
\hline Canela-preta & & & & & & & & & 4,2 & 0,5 & & \\
\hline Capororoca & & & & & & & 12,5 & 5,7 & & & & \\
\hline Crotalária & 28,6 & 45,5 & & & & & & & & & & \\
\hline Desconhecidas & 28,6 & 27,2 & & & 6,3 & 0,4 & 16,7 & 3,8 & 12,5 & 0,8 & 9,1 & 3,3 \\
\hline Guaçatunga & & & & & 37,4 & 82,3 & 12,5 & 36,3 & 12,5 & 10,2 & & \\
\hline Ipomea & 28,6 & 18,2 & & & & & & & & & & \\
\hline Miguel-pintado & & & & & & & & & & & 9,1 & 1,1 \\
\hline Pimenteira & & & & & & & 12,5 & 9,6 & 25,0 & 8,7 & 27,3 & 70,3 \\
\hline Piperaceae & & & & & & & & & 4,2 & 0,2 & & \\
\hline Vacum & & & & & & & 4,1 & 6,4 & & & & \\
\hline Vassourão-branco & & & & & & & 25,0 & 32,5 & 33,3 & 78,8 & 54,5 & 25,3 \\
\hline Vassourão-preto & & & 100 & 100 & 50,0 & 16,4 & 4,2 & 1,9 & & & & \\
\hline$\%$ total & 100 & 100 & 100 & 100 & 100 & 100 & 100 & 100 & 100 & 100 & 100 & 100 \\
\hline Bracatinga & 28,6 & 3,6 & & & & & & & 5,0 & 0,1 & & \\
\hline Canela & & & & & 7,7 & 0,3 & & & & & & \\
\hline Capororoca & & & & & & & 4,0 & 0,7 & 5,0 & 0,1 & 4,0 & 0,7 \\
\hline Carvalho & & & & & & & & & 5,0 & 0,2 & & \\
\hline Cipó & & & & & 7,7 & 0,1 & & & & & & \\
\hline Compositae & & & & & & & 4,0 & 3,2 & & & 4,0 & 3,2 \\
\hline Desconhecidas & 14,2 & 1,8 & & & 7,7 & 0,1 & 28,0 & 3,6 & 5,0 & 0,3 & 28,0 & 3,6 \\
\hline Imbuia & & & & & & & & & 5,0 & 0,4 & & \\
\hline Miguel-pintado & & & & & & & & & 10,0 & 0,2 & & \\
\hline Pessegueiro-bravo & 57,2 & 94,6 & 57,2 & 31,3 & & & 4,0 & 0,2 & & & 4,0 & 0,2 \\
\hline Pimenteira & & & & & & & & & 5,0 & 0,1 & & \\
\hline Vacum & & & & & & & 4,0 & 5,6 & 5,0 & 0,2 & 4,0 & 5,6 \\
\hline Vassourão-branco & & & & & & & 28,0 & 38,3 & 50,0 & 97,6 & 28,0 & 38,3 \\
\hline Vassourão-preto & & & 42,8 & 68,7 & 76,9 & 99,5 & 28,0 & 48,4 & 5,0 & 0,8 & 28,0 & 48,4 \\
\hline$\%$ total & 100 & 100 & 100 & 100 & 100 & 100 & 100 & 100 & 100 & 100 & 100 & 100 \\
\hline
\end{tabular}


Em outubro ocorreu um aumento na produção destes e em novembro e dezembro houve a maior taxa de produção, sendo também os meses de maior diversidade de espécies. Em janeiro ocorreu novamente um declínio, mostrando uma flutuação do fluxo de diásporos bem acentuada nos seis meses estudados.

As espécies com maior número de sementes foram Vernonia discolor (vassourão-preto) e Piptocarpha angustifolia (vassourão-branco), entretanto os seus valores na regeneração natural foram baixos, atribuindo-se este fenômeno principalmente ao fato de serem espécies pioneiras com exigência maior de luz para iniciar a germinação. Outra espécie com altos valores de freqüência e abundância na chuva de sementes foi Prunus sellowii (pessegueiro-do-mato), nos meses de agosto/setembro, sendo a principal forma de dispersão local (liberação direta dos frutos pela planta mãe), a qual também foi encontrada no banco de sementes no solo e abundante na regeneração natural. Entretanto, nas unidades amostradas a espécie Prunus sellowii apresentou um banco de plântulas com um grande número de indivíduos, porém teve uma redução drástica nas categorias de tamanho mais avançadas.

\section{CONCLUSÕES}

a) Apesar de Araucaria angustifolia ser a espécie dominante no estrato superior da floresta, principalmente no Tipo Florestal I, não apresenta indivíduos na regeneração natural.

b) $\mathrm{Na}$ composição do banco de sementes no solo predominam as espécies pioneiras. Mimosa scabrella é a espécie arbórea mais importante presente no banco de sementes no solo. $\mathrm{O}$ índice de diversidade do banco de sementes no solo é maior na área onde não predomina Araucaria angustifolia no estrato superior.

c) As espécies vegetais têm um comportamento bastante irregular de distribuição nos três parâmetros avaliados (regeneração natural, banco de sementes e chuva de sementes), ou seja, são bastante representativas em um parâmetro e pouco em outro(s).

d) Recomenda-se que estudos desta natureza, principalmente no caso de florestas primárias, tenham duração mínima de um ano ou até mesmo dois anos, devido a grande sazonalidade na produção e acumulação de sementes no solo e devido a espécies que florescem e frutificam em períodos superiores a um ano.

\section{AGRADECIMENTOS}

Os autores agradecem aos Profs. Ademir Reis da UFSC e Adelino Alvarez Filho da UFSM e aos mateiros Osvaldo e Lara da EPAGRI pela colaboração na identificação botânica. Agradecimentos vão também a CNPq e à EPAGRI pelo auxílio financeiro.

\section{REFERÊNCIAS BIBLIOGRÁFICAS}

BUDOWSKI, G. Distribution of tropical American rain forest species, in the light of successional processes. Turrialba, México, v. 15, n.1, p.40 - 42, 1965.

CARVALHO, J.O. P. Manejo de regeneração natural de espécies florestais. Belém: EMBRAPA - CPATU, 1984. 22 p. 
DA CROCE, D. M. Caracterização espacial estrutural e fitossociológica da Reserva Genética Florestal de Caçador - SC, através da análise de componentes principais e sistemas de informações geográficas. Santa Maria, 1991. 147 p. Dissertação ( Mestrado em Engenharia Agrícola) - Centro de Ciências Rurais, Universidade Federal de Santa Maria.

DANIEL , O.; JANKAUSKIS, J. Avaliação de metodologia para o estudo do estoque de sementes do solo. SÉRIE IPEF, Piracicaba, v. 41-42, p.18-26, 1989.

DARWIN, C. Origem das Espécies. Belo Horizonte: Ed. Itatiaia, São Paulo, 1985. 366 p.

FINOL, U. H. Nuevos parámetros a considerarse en el análisis estrutural de las selvas virgens tropicales. Rev. For. Venez., Merida, v. 14, n.21, p.29-42, 1971.

GARWOOD, N. C. Tropical Soil Seed Banks: a Review. In: LECK, M. A.; PARKER, T. V.; SIMPSON, R. L. eds. Ecology of soil seed banks. New York: Academic Press. 1989. p. 49210.

GOREEESIO-ROIZMAN, L. G. Fitossociologia e dinâmica do banco de sementes de populações arbóreas de floresta secundária em São Paulo, SP. São Paulo, 1993. 184 p. Dissertação (Mestrado em Ecologia) - Setor de Ecologia, Universidade de São Paulo.

KAGEYAMA, P. Y.; CASTRO, C.F.A.; CARPANEZZI, A. A. Implantação de matas ciliares: estratégias para auxiliar a sucessão secundária. In: SIMPÓSIO SOBRE MATA CILIAR (1989: São Paulo). Anais... Campinas: Fundação Cargill. 1989. p.130-143.

LONGHI, S. J. A estrutura de uma floresta natural de Araucaria angustifolia (Bert.) O. Ktze no sul do Brasil. Curitiba, 1980. 198 p. Dissertação (Mestrado em Ciências Florestais) - Setor de Ciências Agrárias, Universidade Federal do Paraná.

NOGUEIRA, J. C. B. ; NOGUEIRA, L. T. Regeneração natural de mata ciliar na Estação Ecológica de Bauru. Revista do Instituto Florestal, Piracicaba, v. 3, n. 2, p. 157- 162, 1991.

SCHIMTZ, M. C. Banco de sementes no solo em áreas do reservatório da UHE Paraibuna. In: KAGEYAMA, P. Y. Recomposição da vegetação com espécies arbóreas nativas em reservatórios de usinas hidrelétricas da CESP.. SÉRIE IPEF, Piracicaba, v. 8, n.25, p. 7-8, out. 1992.

SIMPSON, R. L; LECK, M. A.; PARKER, V. T. Ecology of Soil Seed Banks. California: Academic Press, 1989. 385 p.

VÁSQUEZ-YANES, C. ; OROZCO-SEGOVIA, A. Seed viabillity, longevity and dormancy in Tropical Rain Forest. México, Centro de ecologia, UNAM, [19--]. 